\title{
A CERÂMICA GUARANI DO SÍTIO RAGIL I
}

\author{
Julia Araujo Carvalho \\ Universidade Estadual Paulista - UNESP. E-mail: juhlcarvalho@hotmail.com
}

\section{RESUMO}

A pesquisa apresenta a cerâmica do Sítio Arqueológico Ragil I, localizado no Município de lepê, SP. Trata-se de um sítio de grupo indígena Guarani, que ocupou o Oeste Paulista no período de 205 a 1880 anos antes do presente. Na busca por identificar a cadeia operatória de produção da cerâmica Guarani do Sítio Ragil I, a fim de conhecer sua funcionalidade e, assim, levantar hipóteses sobre as práticas culturais presentes na área desse sítio utilizou-se a metodologia da análise tecnotipológica, a fim de caracterizá-los em um modo de produção. A cerâmica foi classificada na Tradição Tupiguarani, grupo indígena Guarani.

Palavras-Chave: Sítio Ragil I, Cerâmica, cadeia operatória

\section{THE CERAMICS OF THE RAGIL I ARCHAELOGICAL SITE}

\section{ABSTRACT}

The research presents the ceramics of the Ragil I Archaeological Site, located in the city of lepê, SP. It is a site of Guarani indigenous group, which occupied the West Paulista from 205 to 1880 years before the present.In the search to identify the production chain of Guarani ceramics of the site Ragil I, in order to know its functionality Thus, to raise hypotheses about the cultural practices present in the area of this site, the methodology of technotypological analysis was used in order to characterize them in a mode of production. The pottery was classified in the Tupiguarani Tradition, Guarani indigenous group.

Keywords: Ragil I Site, Ceramics, operative chain

\section{INTRODUÇÃO}

A pesquisa identificou a cadeia operatória de produção da cerâmica Guarani do Sítio Arqueológico Ragil I, por meio do método de análise tecnotipológica de materiais cerâmicos, a fim de conhecer sua funcionalidade e, assim, levantar hipóteses sobre as práticas culturais presentes na área desse sítio.
O sítio está localizado no Município de lepê, Estado de São Paulo, próximo a nascente da Água do Caracol, em seu lado direito, que após percorrer 950 metros deságua no Rio Paranapanema (Figura 1). 
Figura 1. Localização do Sítio Ragil I. I

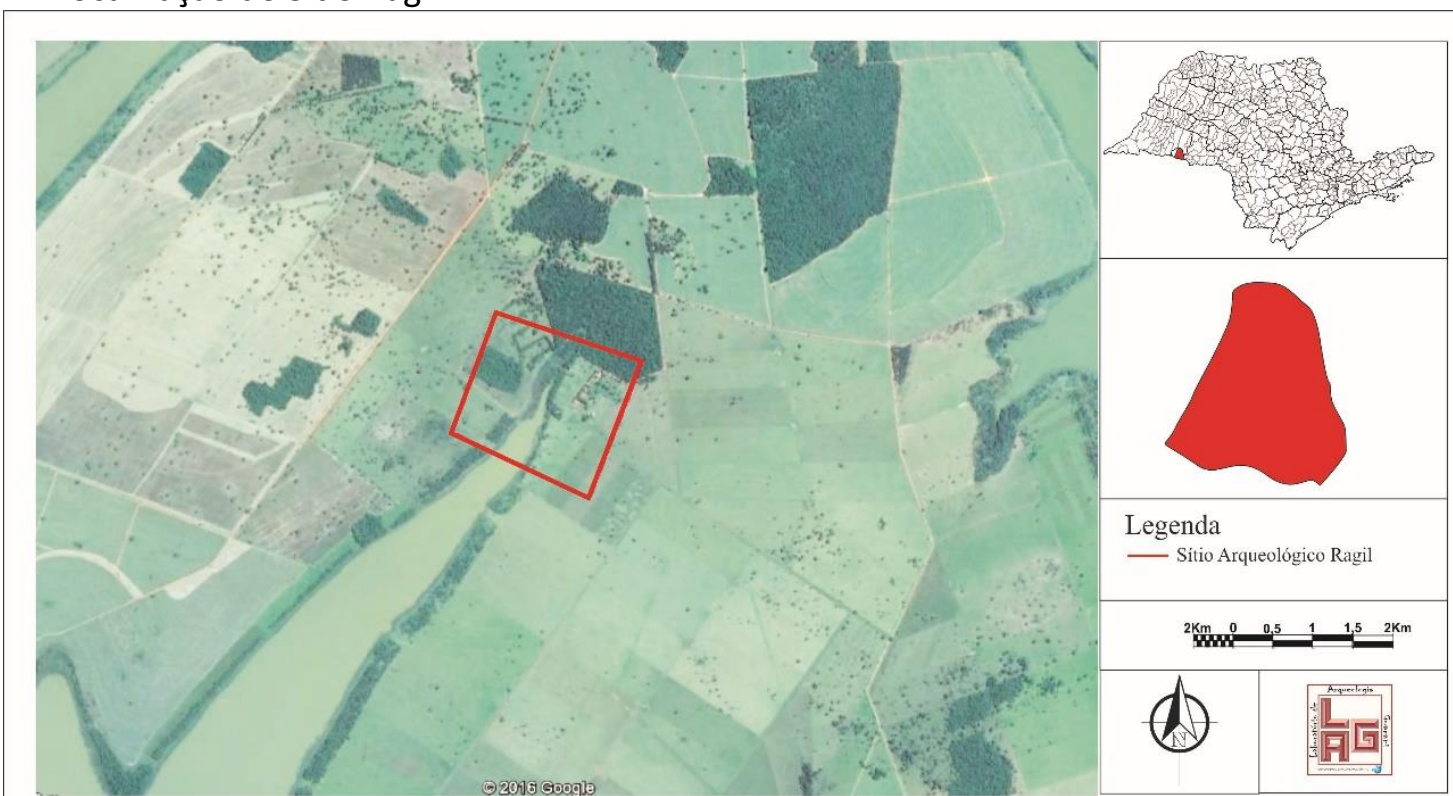

Fonte: Adaptado de Faccio (2011).

A área de entorno do Sítio Arqueológico Ragil I foi ocupada por grupo indígena Guarani, no período que data de aproximadamente 205 a 1880 anos antes do presente (Faccio, 2011).

O sítio, apresenta ainda, nove peças líticas polidas em basalto, arenito e osso calcificado e 324 líticos lascados (Faccio, 2011).

\section{O contexto do Sítio Arqueológico Ragil I}

Os estudos arqueológicos no Município de lepê, SP, começaram no ano de 1993 na propriedade rural do Senhor Roberto Ekman Simões por meio do estudo de materiais cerâmicos por ele encontrados e guardados em caixas que foram classificadas como peças Guarani após análise. O Senhor Roberto também disponibilizou informações acerca da localização de áreas em que se poderiam encontrar mais exemplares em sua propriedade e nas propriedades de seus familiares (FACCIO, 2011).

Trata-se de um Sítio Arqueológico Guarani datado de aproximadamente 1880 antes do presente, o mais antigo sítio arqueológico situado no Município de lepê, SP. Seu material arqueológico encontra-se fragmentado e com muitas rachaduras devido a ação do intemperismo, da ação hídrica, além do uso de arado no local e do pisoteamento do solo pelo gado nos últimos anos, onde a área fora utilizada como pastagem. Trata-se de uma ocupação de grande porte.

\begin{abstract}
Dos sítios arqueológicos de lepê em análise, o Sítio Ragil é o que apresenta a cerâmica em pior estado de conservação. São peças ressecadas, com barbotina craquelada, onde a decoração pintada, se realmente ocorreu, dificilmente pode ser vista (FACCIO, 2015, p. 123).
\end{abstract}

Quando comparados os fragmentos cerâmicos do Sítio Ragil I com os fragmentos dos demais sítios do município, segundo Faccio, verifica-se que, os fragmentos em melhor estado de conservação são aqueles provenientes de sítios submersos, uma vez que apresentam fragmentos maiores e com barbotina intacta, isso porque a fragmentação causada pela ação da água aparenta ser menos agressiva que a ação causada por arado, pisoteamento de gado ou esmagamento por pneus de carro ou de trator. 
Devido às atividades em realização na área, sobretudo a pastagem, não é possível identificar manchas pretas na região do sítio.

\section{A cerâmica do Sítio Arqueológico Ragil I}

A cerâmica do Sítio Ragil I foi analisada por Faccio (1992, 1998). Outros 59 fragmentos cerâmicos desse sítio foram objeto de análise desta pesquisa.

O material cerâmico do Sítio Arqueológico Ragil I deriva muito provavelmente da fonte de argila localizada na nascente da Água do Caracol, localizado dentro da área do sítio.

O material cerâmico do Sítio Ragil é proveniente dos cortes de verificação, áreas de decapagem e coleta de superfície. Pelo fato de a indústria do Sítio Ragil não ter apresentado peças inteiras, 0 primeiro

encaminhamento proposto para análise do material foi o de agrupar os fragmentos de uma mesma vasilha em conjuntos (FACCIO, 2011, p. 223).
O procedimento inicial realizado por Faccio resultou na formação de dez conjuntos apenas, caracterizando o estado de conservação do sítio como perturbado e em alguns pontos como bem conservado.

O estudo da cerâmica do sítio arqueológico impõe aos pesquisadores algumas limitações devido a fragmentação e dispersão de suas peças. Consiste basicamente em paredes, de grossa espessura que, raramente permitem identificação de seus motivos, inclusive da presença ou não de barbotina em seu tratamento.

Com exceção das bases, todas as peças do Sítio Ragil I foram confeccionadas a partir da técnica de acordelamento/roletamento.

\section{A cerâmica analisada}

Nesta pesquisa foi trabalhado parte do Sítio Ragil I, pois este se insere em parte em área de depressão e em parte em área submersa nas águas do Lago da UHE da Capivara. Quando baixa o nível das águas do referido lago, percebe-se a ação hídrica sobre as estruturas arqueológicas. Ainda é nítido que o arado mecânico foi utilizado na área do sítio antes da formação do lago da UHE da Capivara.

As peças cerâmicas analisadas para a área do Sitio Arqueológico Ragil I são apresentadas na Tabela 1.

Tabela 1. Categorias de fragmentos do Sítio Arqueológico Ragil I

\begin{tabular}{lll} 
Tipos de classe & Número de ocorrências & (\%) \\
\hline Parede & 31 & 52,54 \\
\hline Borda & 15 & 25,42 \\
\hline Base & 5 & 8,47 \\
\hline Borda/Parede Angular & 1 & 1,69 \\
\hline Parede Angular & 5 & 8,47 \\
\hline Parede/Base & 2 & 3,38 \\
\hline Total & 59 & 100
\end{tabular}

Fonte: A autora (2019).

Para a confecção das vasilhas foi utilizada a técnica de roletes, exceto as bases, pois foram confeccionadas por modelagem. A partir da análise das peças cerâmicas encontradas na área do Sítio Ragil I, é perceptível a predominância de paredes $(52,54 \%)$ do total, por constituírem a maior parte do corpo da peça.
A coleção cerâmica em estudo apresentou 15 (25,42\%) bordas, todas estão em bom estado e possibilitaram a identificação do diâmetro da boca.

Por fim, foram analisadas cinco bases confeccionadas com a técnica de modelagem. Segundo Brochado e La Salvia (1989), a produção 
de modelagem é a "utilização de uma porção de argila e a partir dela, com os dedos, modela-se a peça pretendida" (BROCHADO; LA SALVIA,1989, p.11).

Segundo Brochado e La Salvia (1989) " O modo de produção, no entanto está vinculado diretamente a pasta. $O$ antiplástico, elemento que pode ser adicionado ou preexistir dentro da argila, diminui a plasticidade desta" (BROCHADO; LA SALVIA, 1989, p.11).

Logo, quanto maior for a quantidade de antiplásticos na vasilha, mais dura ficará a pasta e mais resistente ficará o pote.

$\mathrm{Na}$ área do Sítio Ragil I, o antiplástico que se destacou foi o Mineral associado ao Caco
Moído, com frequência igual a 76,27\%, que equivale a 45 peças. A junção destes dois tipos de antiplásticos torna a peça mais forte e com uma capacidade de suporte para manter as paredes do pote estruturado. Cabe ressaltar, que o antiplástico mineral pode já estar na fonte de matéria-prima ou ter sido inserido junto a argila, como ocorreu com o caco moído.

A Tabela 2 mostra a ocorrência de antiplásticos por tipo, na cerâmica do Sítio Ragil I.

Já a Tabela 3 apresenta as espessuras das paredes da cerâmica do Sítio Ragil I.

Tabela 2. Tipos de antiplásticos apresentados no Sítio Arqueológico Ragil I

\begin{tabular}{ccc}
\hline Tipos de antiplásticos & Número de ocorrências & (\%) \\
\hline Mineral & 11 & 18,46 \\
\hline Mineral/Carvão/Caco Moído & 3 & 5,08 \\
\hline Mineral/Caco Moído & 45 & 76,27 \\
\hline Total & 59 & 100 \\
\hline
\end{tabular}

Fonte: A autora (2019).

Tabela 3. Espessuras das paredes em $\mathrm{cm}$ do Sítio Arqueológico Ragil I Tipos de parede Número de ocorrências

(\%)

\begin{tabular}{ccc}
\hline Finas $(0,1$ a 0,6$)$ & 6 & 10,17 \\
\hline Medias $(0,61$ a 1,0$)$ & 15 & 25,42 \\
\hline Grossas $(1,0$ a 7,0$)$ & 38 & 64,40 \\
\hline Total & 59 & 100 \\
\hline
\end{tabular}

Fonte: A autora (2019).

No Sítio Ragil I predominam as paredes grossas indicando que o artesão adicionou à pasta uma quantidade de antiplásticos, o que possibilitou uma dureza para que esse recipiente pudesse suportar a queima ou suportar o seu peso.

As cerâmicas de paredes médias e finas aparecem na sequência, sendo 15 médias e seis finas. Estas possuem pastas mais plásticas, sendo mais finas e com menor densidade de antiplásticos, o que as tornam menos resistentes.

Para Brochado e La Salvia (1989) a Barbotina é "um revestimento superficial de argila mais refinada, aplicado a cerâmica antes da queima" (p. 17). O uso da Barbotina tem seus benefícios: maior resistência na fixação dos roletes; maior resistência a ação dos elementos a serem utilizados, quer na produção de alimentos, na guarda, para consumo posterior; a diminuição da porosidade aumenta a resistência ao impacto, diminuindo a permeabilidade. (BROCHADO; LA SALVIA, 1989, p. 17 - 21).

A aplicação do banho de barbotina é mais frequente na parte interna, sendo que $90 \%$ dos artefatos cerâmicos lisos apresentam esse tipo de tratamento de superfície (BROCHADO; LA SALVIA, 1989, p. 21 - 24).

No Sítio Ragil I, salvo exceções as peças da amostra analisada não apesentam tratamento de suas faces com barbotina (Tabela 4). 
Tabela 4. Presença de tratamento por barbotina nas peças do Sítio Arqueológico Ragil I

\begin{tabular}{ccc}
\hline $\begin{array}{c}\text { Tratamentos de barbotina } \\
\text { Sem barbotina interna/com barbotina } \\
\text { externa }\end{array}$ & Número de ocorrências & (\%) \\
\hline $\begin{array}{c}\text { Com barbotina interna/sem barbotina } \\
\text { externa }\end{array}$ & 5 & 1,69 \\
\hline Com barbotina interna/externa & 0 & 8,47 \\
\hline Sem barbotina interna/externa & 53 & 89,83 \\
\hline Total & 59 & 100
\end{tabular}

Fonte: A autora (2019).

A Tabela 5 mostra que o alisamento da superfície da cerâmica é frequente na área do sítio Ragil I, com 54 peças (91,52\%). O alisamento pode ser feito naturalmente ou com o uso de Barbotina. Segundo Brochado e La Salvia (1989) "sobre uma superfície natural deveríamos ter o uso de um instrumento, o qual não poderá ser identificado mas terá como fim, eliminar rugosidade" ; o mesmo alisamento, mas aplicado em partes, aproveitando a plasticidade da pasta, assim mesmo teria um caráter temporário, pois a aplicação de uma nova sequência de roletes exigiria uma ação de fixação que, pelas características deverá ser mais enérgica; o alisamento, se aplicado no momento em que a peça já está em processo de raspagem elimina as anfruosidades superficiais (BROCHADO; LA SALVIA, 1989, p. 41).

Enquanto a Tabela 6 apresenta a técnica de manufatura na confecção da cerâmica do Sítio Ragil I.

Tabela 5. Tratamento de superfície das peças do Sítio Arqueológico Ragil I

\begin{tabular}{ccc}
\hline Tipo de tratamento & Número de ocorrências & (\%) \\
\hline Alisamento interno/externo & 54 & 91,52 \\
\hline Sem tratamento interno/externo & 5 & 8,47 \\
\hline Total & 59 & 100 \\
\hline
\end{tabular}

Fonte: A autora (2019).

Tabela 6. Técnicas de manufatura apresentadas no Sítio Arqueológico Ragil I

\begin{tabular}{ccc}
\hline Tipo de técnica & Número de ocorrências & (\%) \\
\hline Roletado/Acordelado & 54 & 91,52 \\
\hline Modelado & 5 & 8,47 \\
\hline Total & 59 & 100
\end{tabular}

Fonte: Aautora (2019).

Verifica-se, a partir da análise da Tabela 6, que o acordelado é a técnica predominante. 0 modelado é menos frequente. Contudo, se analisarmos a vasilha como uma unidade de análise verificamos que o corpo da peça é acordelada, ao passo que a base é modelada nos sítios Guarani do Vale do Rio Paranapanema Paulista (FACCIO, 1992, 1998). Assim, a parte da base de uma peça, geralmente é menor que o corpo, principalmente em peças profundas.
Dessa forma, é comum o moldado aparecer em menor frequência que o acordelado em sítios indígenas Guarani.

A maior quantia de peças, no caso 30, correspondentes a $50,85 \%$, indicam que a pasta usada com maior frequência, nesse sítio, foi a de dureza intermediaria (Tabela 7). 
Tabela 7. Dureza das peças analisadas do Sítio Arqueológico Ragil I

\begin{tabular}{ccc}
\hline Pasta & Número de ocorrências & (\%) \\
\hline Dura & 26 & 44,06 \\
\hline Intermediaria & 30 & 50,85 \\
\hline Plástica & 3 & 5,08 \\
\hline Total & 59 & 100 \\
\hline
\end{tabular}

Fonte: A autora (2019).

A pasta constitui-se da junção de argila e antiplásticos. Quanto maior a presença de antiplásticos, menor a proporção da argila na pasta e maior será a dureza e a resistência do pote (Figura 2), quando ambas estiverem com suas quantias relativamente equilibradas, o resultado será uma pasta intermediária (Figura
3), por fim quando houver a predominância de argila esta será plástica (Figura 4).

A Tabela 8 apresenta os tipos de queima apresentados na cerâmica do sítio Ragil I

Figura 2. Pasta dura

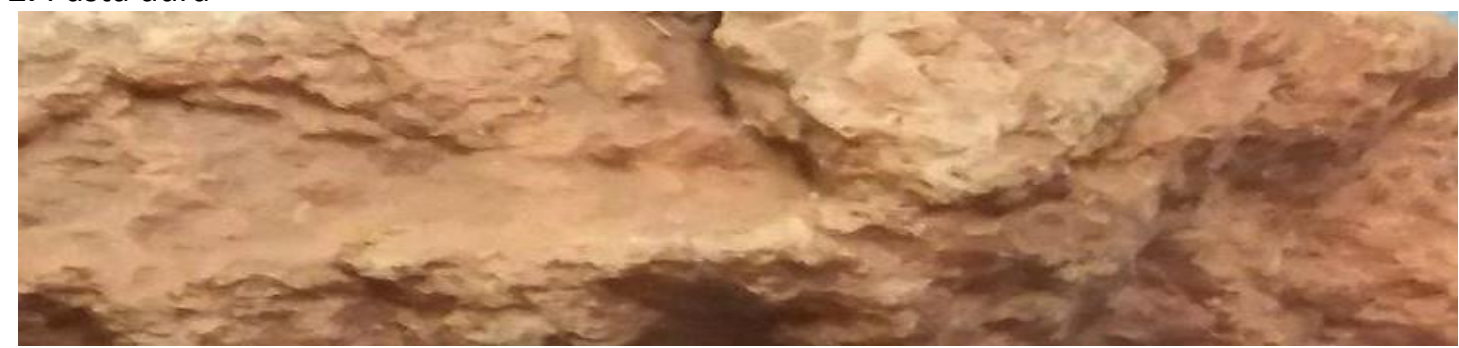

Fonte: A autora (2019).

Figura 3.Pasta intermediaria

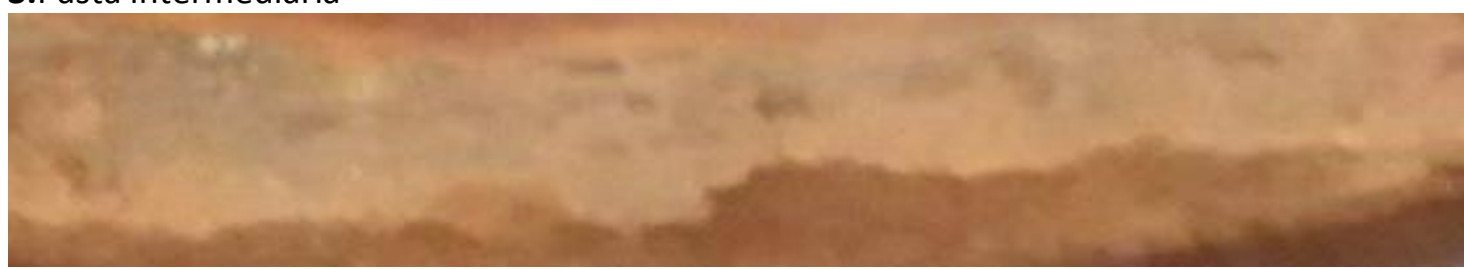

Fonte: A autora (2019).

Figura 4.Pasta plástica

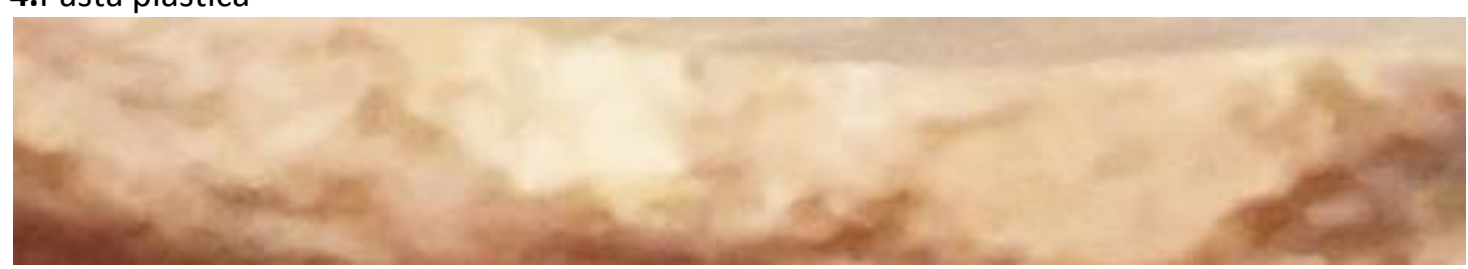

Fonte: A autora (2019). 
Tabela 8. Tipos de queima identificados nas peças do Sítio Arqueológico Ragil I

\begin{tabular}{ccc}
\hline Tipo de queima & Número de ocorrências & (\%) \\
\hline Cor uniforme variando do laranja-tijolo ao amarelo & 13 & 22,03 \\
\hline Cor variando do cinza claro ao pardo & 20 & 33,89 \\
\hline $\begin{array}{c}\text { Núcleo central escuro com uma camada interna e } \\
\text { uma camada externa clara }\end{array}$ & 4 & 6,78 \\
\hline $\begin{array}{c}\text { Cor variando do cinza escuro ao preto } \\
\text { Camada clara na parte externa e escura na parte } \\
\text { interna }\end{array}$ & 19 & 32,20 \\
\hline $\begin{array}{c}\text { Camada clara na parte interna e escura na parte } \\
\text { externa }\end{array}$ & 3 & 5,08 \\
\hline $\begin{array}{c}\text { Total } \\
\text { Total }\end{array}$ & 0 & 0 \\
\hline
\end{tabular}

Fonte: A autora (2019).

Na cerâmica do Sítio Ragil I predomina a queima com núcleo variando do cinza claro ao pardo, ocorrendo em 33,89\% da amostra, indicando uma queima com a qualidade considerada boa, uma vez que se aproxima da queima ideal apresentando cor uniforme, assim sua coloração varia do laranja-tijolo ao amarelo, ocorre em peças expostas a temperaturas altas e pouco variáveis, em locais sem grandes alterações devido a ação do vento.

O segundo tipo de queima apresenta cor uniforme variando do cinza escuro ao preto, indica uma queima incompleta, de má qualidade, ocorrendo em $32,20 \%$ dos casos. Esta ocorre quando a peça é exposta à baixas temperaturas por tempo insuficiente para determinada peça.

Analisando o conjunto de dados, até o momento apresentados, observa-se que não há como estabelecer correlação entre os dados das Tabelas 1, 2 e 8 (categoria da peça, antiplástico e tipo de queima, respectivamente).
Diferente dessa realidade, na Indústria Cerâmica contemporânea, se observa uma homogeneidade e padronização entre os mesmos elementos anteriormente citados, tal fenômeno é derivado do controle da cadeia operatória da cerâmica industrial. Desse modo, inferimos que a forma mais provável do processo de queima das peças se dava a céu aberto, tendo como fator determinante as características do tempo no momento da queima.

A espessura predominante no Sítio Ragil I, em relação ao antiplástico caco moído é a média, ocorrendo com 19 peças (42,22\%), seguida pela variação granulométrica fina com 18 ocorrências (40\%). Em casos raros o caco moído apresenta uma variação de espessura grossa, com ocorrência em 8 peças $(17,78 \%)$, nesses casos as espessuras de parede foram superiores a três centímetros (Tabela 9).

Tabela 9. Variações de espessura do antiplástico

caco moído $(\mathrm{cm})$ no Sítio Arqueológico Ragil I

\begin{tabular}{ccc}
\hline Variações & $\begin{array}{c}\text { Número de } \\
\text { ocorrências }\end{array}$ & $\mathbf{( \% )}$ \\
\hline Fina $(0,1-0,2)$ & 18 & 40 \\
\hline Média $(0,21-0,4)$ & 19 & 42,22 \\
\hline $\begin{array}{c}\text { Grossa }(0,41- \\
0,9)\end{array}$ & 8 & 17,78 \\
\hline Total & 45 & 100 \\
\hline
\end{tabular}

Fonte: A autora (2019).

As ocorrências de granulometria mineral apontam que existe uma predominância da variação granulométrica, sendo ela média em 6 peças $(54,54 \%)$, seguida da granulometria fina em, 4 peças $(36,36 \%)$ e da granulometria grossa em apenas uma peça $(9,10 \%)$ (Tabela 10).

Sobressai-se a granulometria fina, com duas peças $(66,66 \%)$, além disso apresenta um exemplar $(33,33 \%)$ com granulometria media e 
ausência de antiplásticos de granulosidade grossa

(Tabela 11).

Tabela 10. Variações granulométricas do antiplástico mineral (cm) no Sítio Arqueológico Ragil I

\begin{tabular}{ccc}
\hline Variações & $\begin{array}{c}\text { Número de } \\
\text { ocorrências }\end{array}$ & (\%) \\
\hline Fina $(0,1-0,2)$ & 4 & 36,36 \\
\hline Média $(0,21-0,4)$ & 6 & 54,54 \\
\hline Grossa $(0,41-0,9)$ & 1 & 9,10 \\
\hline Total & 11 & 100
\end{tabular}

Fonte: A autora (2019).

Tabela 11. Variações granulométricas do antiplástico carvão $(\mathrm{cm})$ no Sítio Arqueológico Ragil I

\begin{tabular}{ccc} 
Variações & Número de ocorrências & $\mathbf{( \% )}$ \\
\hline Fina $(0,1-0,2)$ & 2 & 66,66 \\
\hline Média $(0,21-0,4)$ & 1 & 33,33 \\
\hline Grossa $(0,41-0,9)$ & 0 & 0 \\
\hline Total & 3 & 100
\end{tabular}

Fonte: Elaborado pela autora (2019).

Como parte do sítio fica submersa, quando o nível das águas baixa as cerâmicas ficam expostas ao sol, secando rapidamente. Após esse período de seca as peças novamente submergem. Esse processo contínuo destrói a pintura das peças e craquela superfícies.
A predominância nesse sítio é de peças que apresentem alisamento interno e externo, ocorrendo 24 vezes. Seguido da decoração caracterizada pelo alisamento na face interna e corrugado na parte externa com 13 peças (22,03\%) (Tabela 12). 
Tabela 12. Tipos de decoração observados nas peças do Sítio Arqueológico Ragil I

\begin{tabular}{ccc}
\hline Tipo de decoração & Número de ocorrências & (\%) \\
\hline Alisamento interno/externo & 24 & 40,68 \\
\hline Alisamento interno/engobo vermelho externo & 2 & 3,39 \\
\hline Engobo vermelho interno/alisamento externo & 2 & 3,39 \\
\hline Alisamento interno/corrugado externo & 13 & 22,03 \\
\hline Engobo vermelho interno/corrugado externo & 3,39 \\
\hline Engobo vermelho interno/inciso externo & 2 & 1,69 \\
\hline Engobo vermelho interno/engobo branco externo & 1 & 3,39 \\
\hline Alisamento interno/ungulado externo & 2 & 3,39 \\
\hline Alisamento interno/pintura associada à engobo branco & 2 & 8,47 \\
\hline externa & 5 & 1,69 \\
\hline Pintura associada à engobo branco interna/alisamento & 1 & 1,69 \\
\hline Engobo vermelho interno/pintura associada à engobo \\
branco externa
\end{tabular}

Fonte: Elaborado pela autora (2019).

A presença de engobo vermelho nesse sítio faz-se notável, além disso, observa-se que o povo que ali habitava utilizava-se da pintura em sua decoração como apresentado nas Figuras 5, 6 e 7 a seguir.

Figura 5. Peça cerâmica número 2631 do Sitio Ragil I

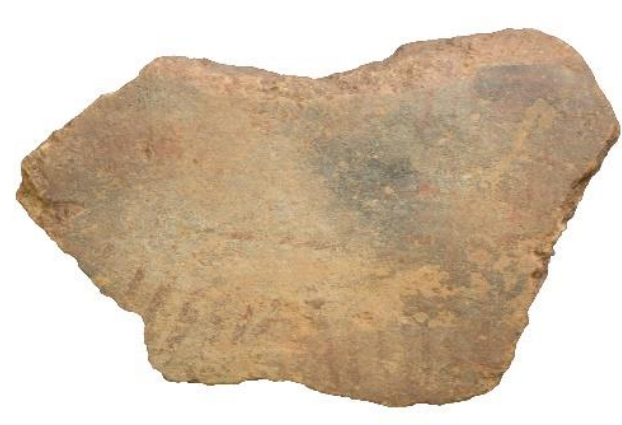

Fonte: A autora (2019).

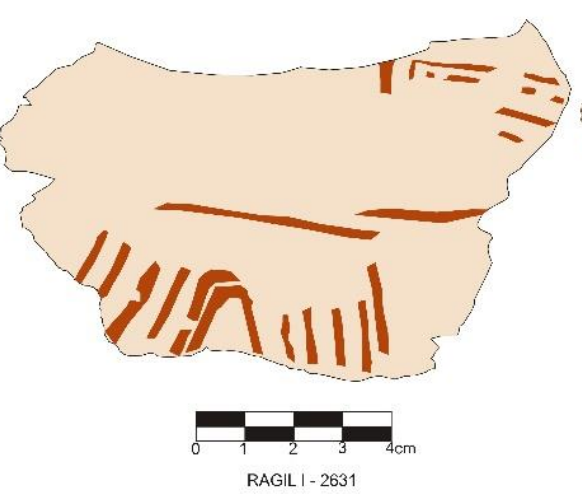

RAGIL I - 2631

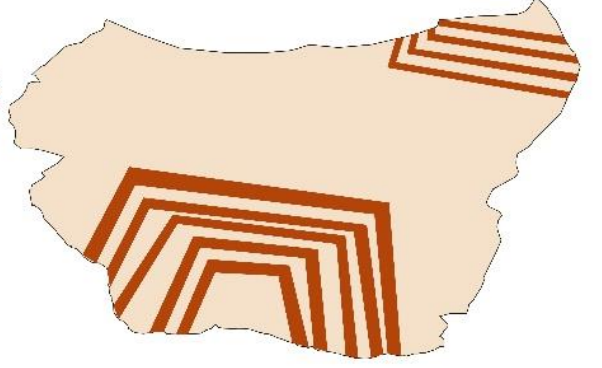


Figura 6. Peça cerâmica número 2635 do Sitio Ragil I
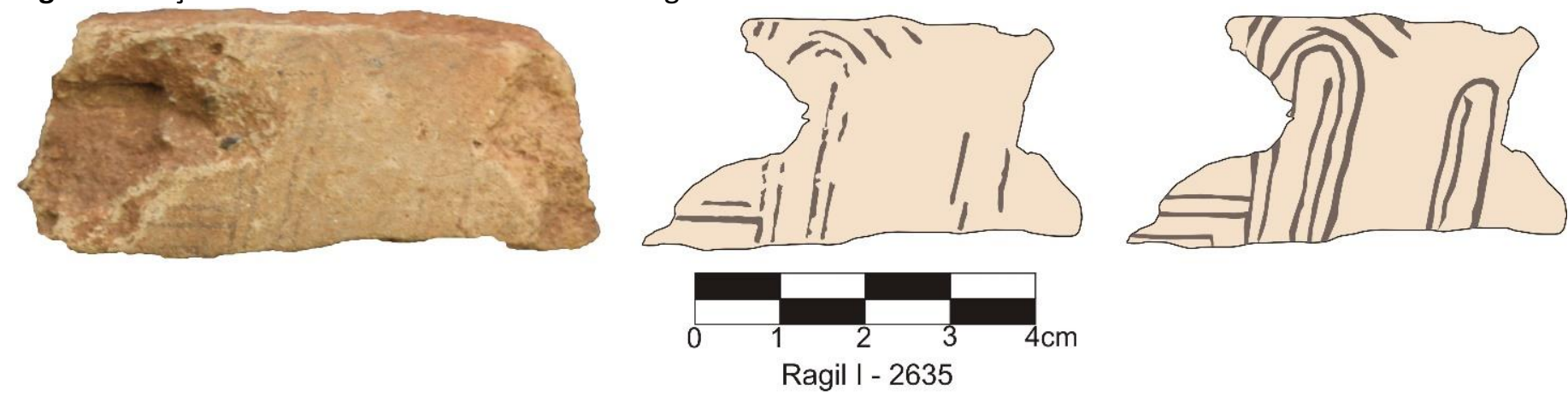

Fonte: A autora (2019).

Figura 7. Peça cerâmica número 2659 do Sitio Ragil I
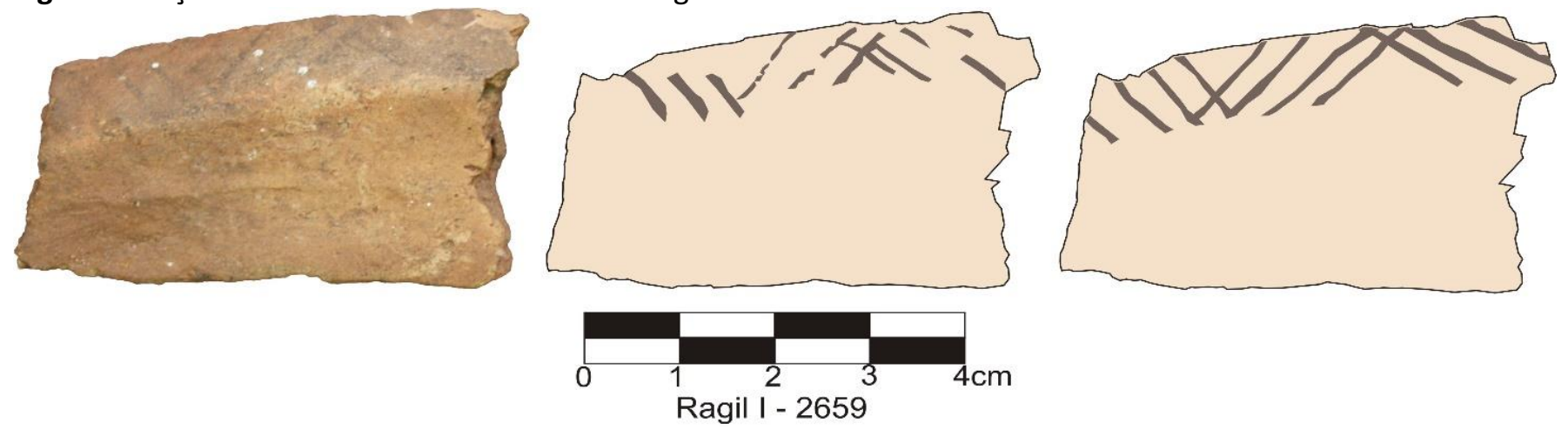

Fonte: A autora (2019).

Reconstituição gráfica da forma das peças, a partir do desenho das bordas

A classificação das bordas do sítio em análise foi feita de acordo com as categorias de classificação de vasilhas exposta por Montoya em seus Dicionários Guarani-Espanhol produzidos entre 1612 e 1616 e publicados em 1639. Brochado e Monticelli (1994) em "Regras práticas na reconstrução gráfica da cerâmica Guarani por comparação com vasilhas inteiras".
As classificações desenvolvidas são elas: cambuchí, cambuchí caguaba, yapepó, nãe, nãe apua e, nãeta.

Ñae: Prato, vasilhas de borda convexa semelhante a Ñamopiu, no entanto são mais profundos que a última (Figura 8) (BROCHADO; MONTICELLI,1994).

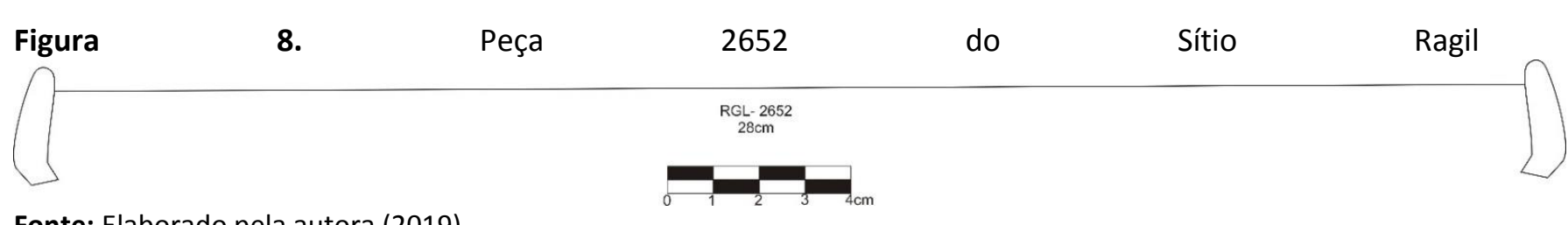

Fonte: Elaborado pela autora (2019).

A peça permite reconstituição total do vaso que se enquadra na classificação de Nãe (prato) que apresenta borda aberta, convexa vertical, com base rasa ou relativamente rasa.

Ñae apua: Escudela, utilizada no consumo de caldos e bebidas quentes, de borda convexa introvertida, caracteriza-se como vasilha profunda apresentando bocal com diâmetro variando de 24 a $36 \mathrm{~cm}$ (Figura 9) (BROCHADO; MONTICELLI,1994); 
Figura 9. Peça 2660 do Sítio Ragil I

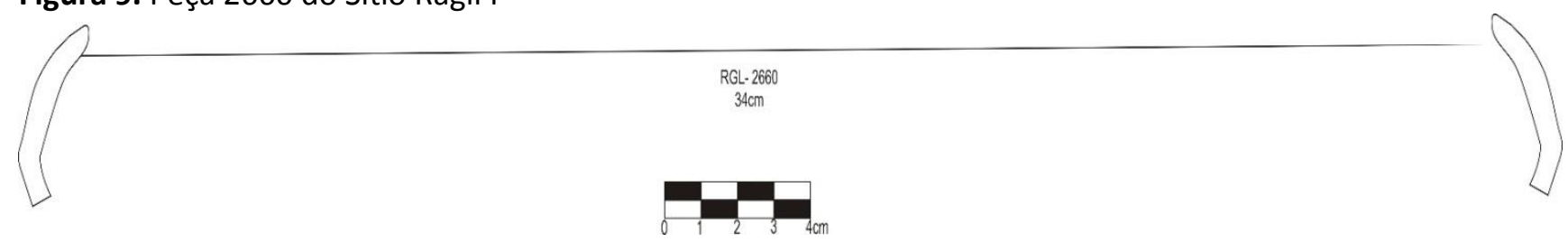

Fonte: Elaborado pela autora (2019).

A peça permite a reconstituição total do vaso com precisão, apresenta borda convexa introvertida. A espessura de sua parede sugere que o vaso não foi produzido com o intuito de ir ao fogo e seu diâmetro evidencia que não se trata de uma Cambuchí caguaba, encaixando-se assim na categoria de Nãe apua (escudela), tipo de vaso utilizado para o consumo de caldos e bebidas quentes.
Nãeta: Caçarola para cozinhar, sua altura pode ultrapassar os $50 \mathrm{~cm}$, mas não fica abaixo dos $12 \mathrm{~cm}$, com o diâmetro da boca de 30 até 70 $\mathrm{cm}$, pois são tigelas muito abertas com a forma conoidal ou elipsoidal, de contorno simples e borda direta, contínua com a paredes, ou convexa, vertical (Figura 10) (BROCHADO; MONTICELLI,1994);

Figura 10. Peça 2666 do Sítio Ragil I

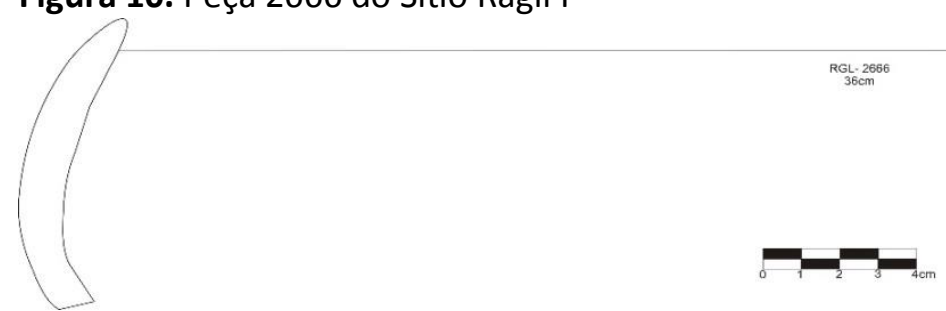

Fonte: Elaborado pela autora (2019).

A peça permite reconstituição total do vaso que apresenta borda convexa introvertida de media profundidade. Trata-se de uma Nãeta (caçarola) de médio porte.
Ainda observamos as Cambuchi Caguâba que são tigelas para beber bebidas fermentadas alcoólicas, também denominadas como caçarolas (QUADRO 1) (BROCHADO; MONTICELLI,1994); 
Quadro 1. Bordas categorizadas como Cambuchi Caguaba

\section{CAMBUCHI CAGUABA}
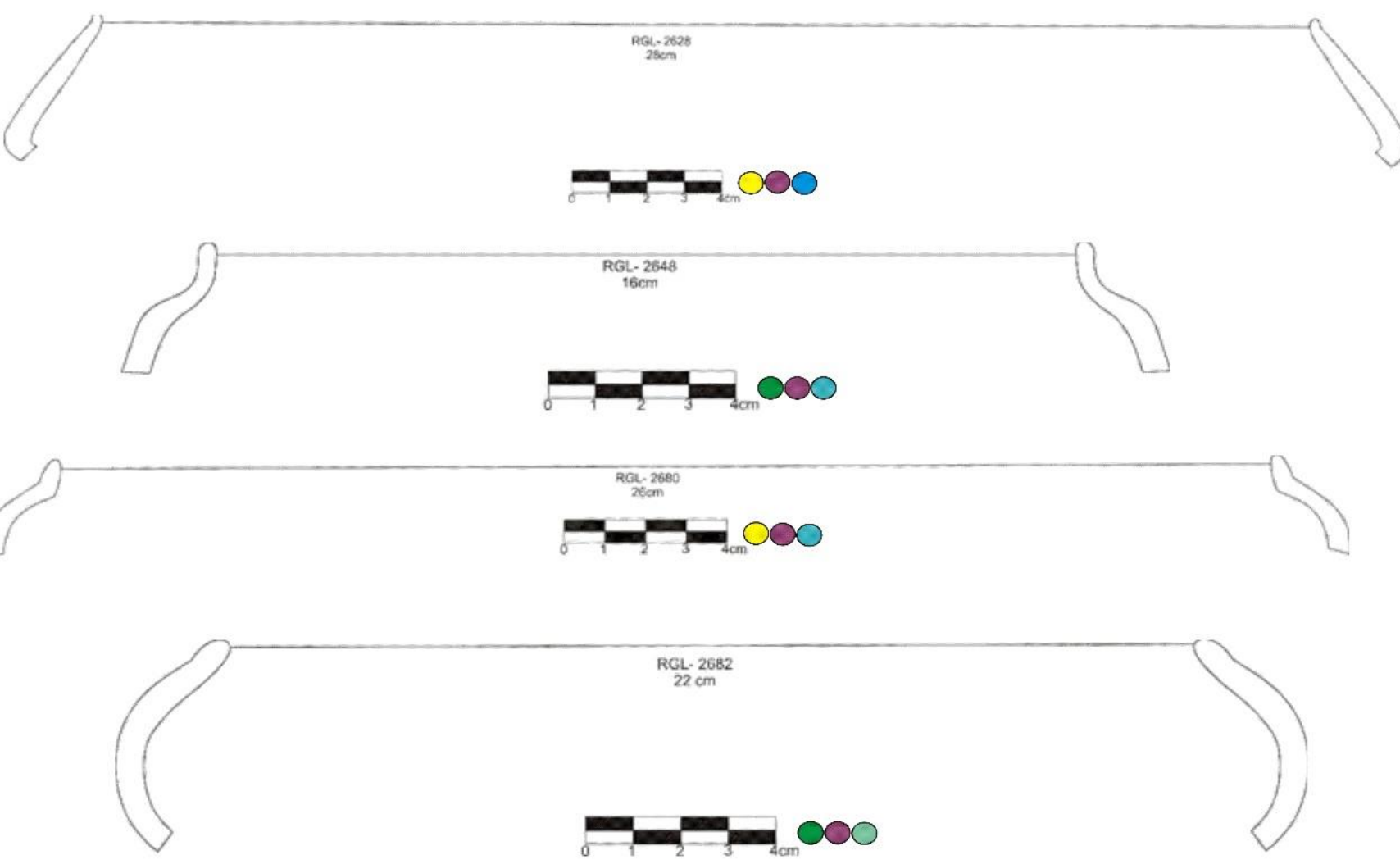

ELABORAÇÃO: CARVALHO, J. A (2019)

SIITIO ARQUEOLÓGICO RAGIL I

INTROVERTIDO

EXTROVERTIDO

VERTICAL

INFLETIDO

घSEÇÃO SUPERIOR RESTRINGIDA
PPEQUENO PORTE

MÉDIO PORTE

GRANDE PORTE

CONVEXO

CÔNCAVO

PRANCHA 1

LABORATÓRIO DE ARQUEOLOGIA GUARANI

Fonte: A autora (2019).

Observa-se a predominância de cerâmicas de médio porte categorizadas como Cambuchi Caguaba, permitindo-nos à especulação acerca da partilha da bebida, elemento que difere da tradição europeia, que vige sobre grande parte dos territórios colonizados.
Cambuchi: Tem por definição etnológica de talha, com utilidade de fermentar, armazenar e servir bebidas fermentadas alcoólicas e, secundário, para enterramento, quando pintadas externamente elas não iriam ao fogo (NOELLI, 1993, apud, DAVES, 2016). 
Quadro 2. Bordas categorizadas como Cambuchi

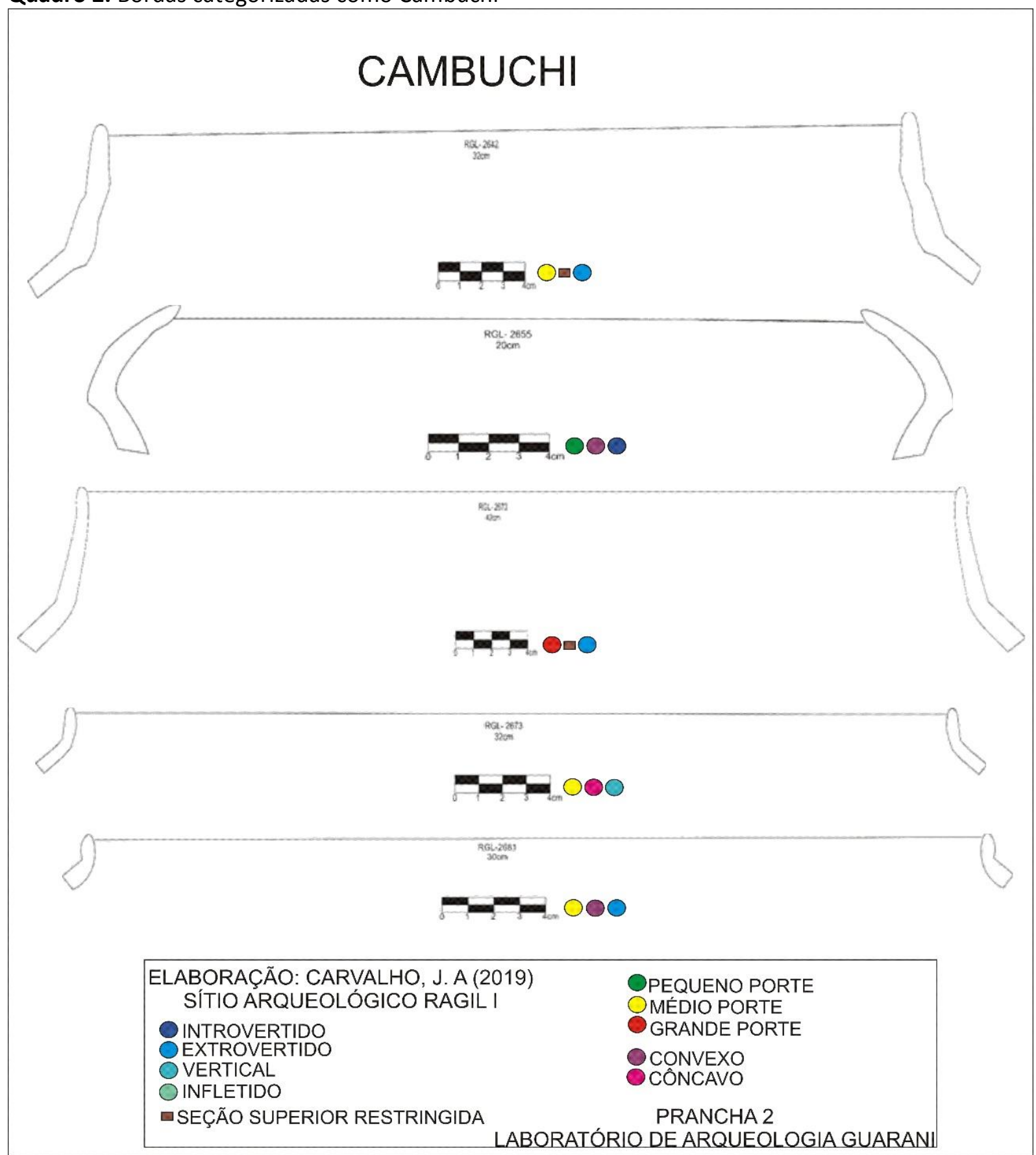

Fonte: A autora (2019).

A análise das bordas categorizadas nos permite inferir que aqueles que produziram as peças analisadas, se organizavam em grupamentos humanos médios e pertenciam ao povo Guarani.

Yapepó: Exerce a função de panela com o uso principal sobre o fogo para cozinhar e, frequentemente utilizada secundariamente como urna funerária, as dimensões variam entre 60 a
$70 \mathrm{~cm}$ de altura e entre 12 e $80 \mathrm{~cm}$ de diâmetro na boca. Apresenta-se em sua base a forma conoidal ou quando de pequenas dimensões, arredondadas e, suas paredes são infletidas, em geral fortemente convexas, formando um bojo pronunciado. A borda desse tipo de vasilha cerâmica correspondente ao formato côncava, vertical, ligeiramente inclinada para dentro ou para fora (NOELLI, 1993, apud, DAVES, 2016). 
Quadro 3. Bordas categorizadas como Yapepó

\section{YAPEPÓ}
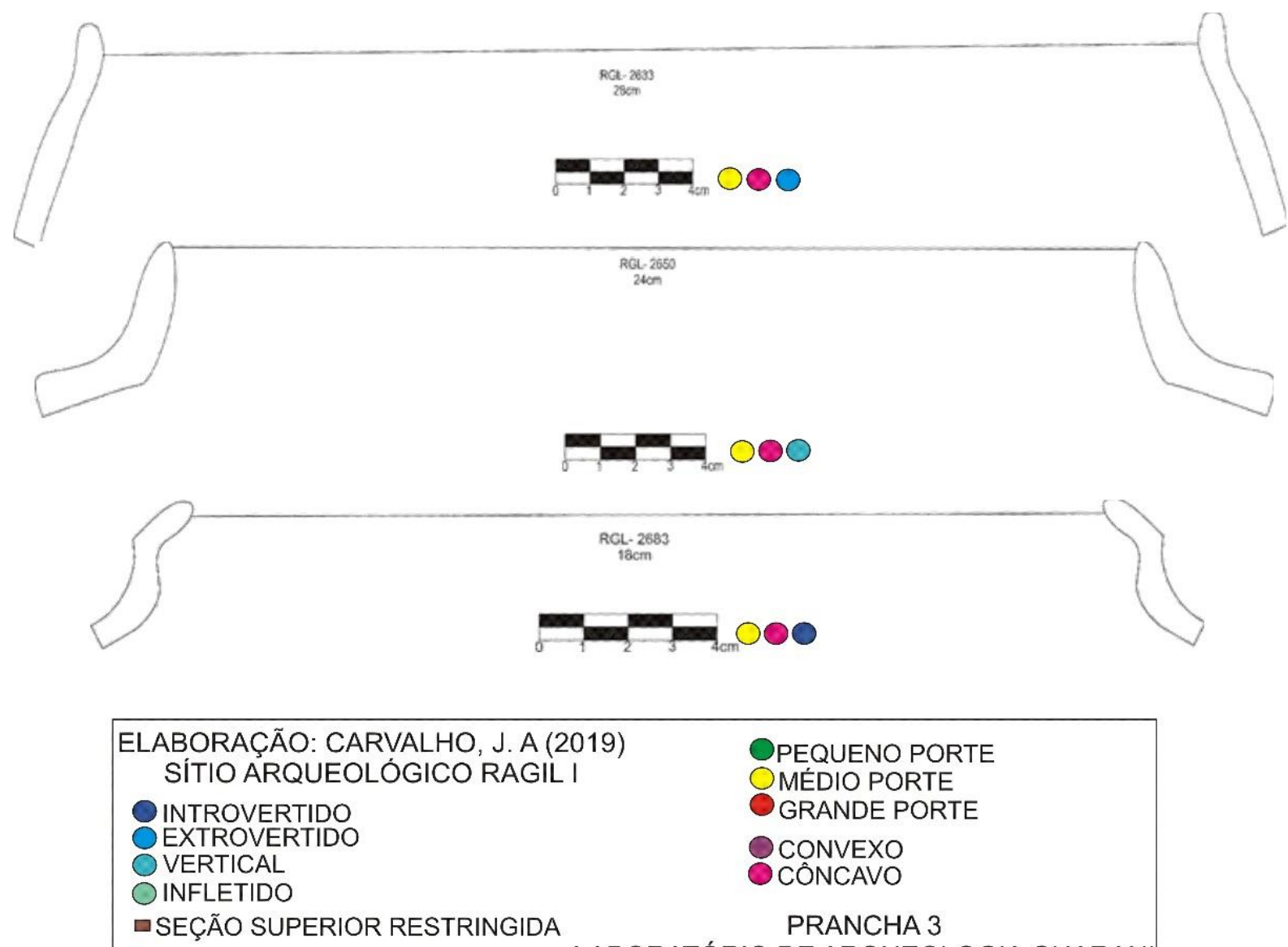

PEQUENO PORTE

OMÉDIO PORTE

GRANDE PORTE

CONVEXO

CÔNCAVO

PRANCHA 3

Fonte: A autora (2019).

As Yapepó são como as panelas, os utensílios levados ao fogo para o preparo de alimentos, sendo assim seu porte, remete diretamente na demanda de alimento a ser preparado e consequentemente no número de pessoas dependentes de um preparo único.

\section{CONCLUSÃO}

O estudo da amostragem composta por 59 peças do Sítio Ragil permitiu a formação de três conjuntos compostos por duas, três e cinco peças, caracterizando o mesmo como sítio razoavelmente conservado. Os conjuntos de fragmentos de um mesmo pote possibilitaram a formulação de hipóteses a respeito da função das vasilhas.
O estudo da cerâmica permitiu sua classificação na Tradição Tupiguarani, pertencente à um grupo indígena Guarani, além de identificar as condições de conservação do sítio arqueológico, a distribuição de recursos minerais da localidade e permitiu a formulação de hipóteses acerca da função das vasilhas cerâmicas, assim como o padrão gráfico utilizado pela sociedade analisada.

$\mathrm{O}$ fato de a grande maioria das bordas analisadas sugerirem cerâmicas de médio porte, nos permite identificar que mesmo dentro de sítios são classificados como de grande porte, havia uma subdivisão em grupos menores dentro de um mesmo território indígena.

\section{REFERÊNCIAS}

BROCHADO, J. P. LA SALVIA E. Cerâmica Guarani. Porto Alegre: Posenato Arte \& Cultura, 1989.

BROCHADO, J. J. P. \& MONTICELLI, G. Regras práticas na reconstrução gráfica da cerâmica 
Guarani a partir dos fragmentos. Estudos Iberoamericanos v. XX, n02, Pucrs, 1994.

DAVES, Larissa Figueiredo. A paisagem cultural do sitio arqueológico piracanjuba, Piraju, SP. 2016. 163 f. Trabalho de Graduação de Curso (Bacharel em Geografia) - Universidade Estadual Paulista. Presidente Prudente: UNESP, 2016.

Faccio, Neide Barrocá. Estudo do Sítio Arqueológico Alvim no Contexto do Projeto Paranapanema. Dissertação de Mestrado. São Paulo: Faculdade de Filosofia, Letras e Ciências Humanas, Universidade de São Paulo, 1992.

Faccio, Neide Barrocá. Arqueologia dos Cenários das Ocupações da Capivara, Baixo Paranapanema. Tese de doutorado. São Paulo: Faculdade de Filosofia, Letras e Ciências Humanas, Universidade de São Paulo, 1998.

FACCIO, Neide Barroca. Arqueologia Guarani na área do projeto Paranapanema: estudo dos sítios de lepê, SP. 2011. 401 f. Tese (Livre-Docência em Museu de Arqueologia e Etnologia) Universidade de São Paulo, São Paulo, 2011.

FACCIO, Neide Barroca. Os Sítios Arqueológicos Guarani do Município de lepê, Estado de São Paulo. Revista Museu Arqueologia e Etnologia. v.25, p. 119-131, 2015. https://doi.org/10.11606/issn.2448-

1750.revmae.2015.114974

NOELLI, Francisco Silva. Sem Tekoha não há Tekó: em busca de um Modelo Etnoarqueológico da Aldeia e da Subsistência Guarani e sua aplicação a uma área de domínio no Delta do Jacuí - RS. 1993. Dissertação (Mestrado em História Ibero-Americana) - Pontifícia Universidade Católica do Rio Grande do Sul. Porto Alegre: PUCRS, 1993. 